\title{
Radiotherapy Delivering in COVID-19 Pandemic Context. Galati Radiotherapy Center's Experience and Recommendations of Professional Societies
}

\author{
Laura REBEGEA ${ }^{1,2}$, Rodica ANGHEL ${ }^{3}$, Aurel NECHITA ${ }^{4}$, Dorel FIRESCU ${ }^{5,6}$, Xenia BACINSKI ${ }^{3}$, \\ Mihaela DUMITRU', Mihaela CRAESCU1,7
}

\begin{abstract}
COVID-19 pandemic represents a challenge for entire medical world, with profound implications in daily practice, making a compromise between risk of infection with SARS-COV2 and oncological treatment continuing, in conditions in which must be balanced, for each patient, the risk of infection with COVID-19.

We are presenting the recommendations of professional societies and actions take in Radiotherapy Department of "Sf. Ap. Andrei" Emergency Clinical Hospital, Galati in order to limit the spread of COVID-19 infection and concomitant with radiotherapy performing, without compromising the quality of medical act.
\end{abstract}

Keywords: COVID-19, radiotherapy, recommendations.

\section{Rezumat}

Pandemia cu COVID-19 reprezintă o provocare pentru întreaga lume medicală, cu implicații profunde în practica zilnică, ajungându-se la un compromis între riscul de infecție cu SARS-COV2 și continuarea tratamentelor oncologice, în condițiile în care trebuie gândit pentru fiecare caz în parte, riscul infecției cu COVID-19.

Prezentăm recomandările societăților profesionale și acțiunile întreprinse în Centrul Radioterapie Galați pentru limitarea răspândirii infecției cu COVID-19 concomitent cu efectuarea radioterapiei, fără compromiterea calității actului medical.

Cuvinte cheie: COVID-19, radioterapie, recomandări.

\footnotetext{
${ }^{1}$ Department of Radiotherapy, „Sf. Apostol Andrei" Emergency Clinical Hospital, Galati, Romania

${ }^{2}$ Medical Clinical Department, Faculty of Medicine and Pharmacy,

„Dunarea de Jos" University, Galati, Romania

3 "Carol Davila" University of Medicine and Pharmacy", Bucharest,

Romania

${ }^{4}$ Department of Dentistry, Faculty of Medicine and Pharmacy, „Dunarea de Jos" University, Galati, Romania

${ }^{5}$ IId Clinic of Surgery, „Sf. Apostol Andrei" Emergency Clinical Hospital, Galati, Romania

${ }^{6}$ Surgical Clinical Department, „Dunarea de Jos" University,

Faculty of Medicine and Pharmacy, Galati, Romania

${ }^{7}$ Department of Morphopathology, Faculty of Medicine and

Pharmacy, "Dunarea de Jos" University, Galati, Romania
}

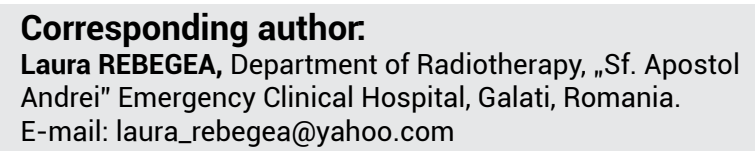


COVID-19 pandemic represents a challenge for entire medical world and also for multidisciplinary oncology team and professional societies, in order to reduce the impact of this pandemic, thought out recommendations regarding radiotherapy performing and emitted international guides.

This pandemic have profound implications in daily practice, in which must be balanced, for each patient, the risk of infection with COVID-19 and radiotherapy benefit, making a compromise between risk of infection with SARS-COV2 and oncological treatment continuing, respective, chemotherapy and radiotherapy.

Delay of oncological treatment performing decreases surviving chances for patients, increases local, regional and distant relapse risk.

On $27^{\text {th }}$ of April 2020, at the moment of writing this article conforming to Public Health Institute of Bucharest, Romania, were recorded 2870644 of COVID-19 cases, and 203350 deaths, worldwide. Important increases of cases number were recorded in USA, Italy, France, Iran, and Turkey. In Romania, until 26th of April 2020, were recorded 11.036 new cases infected with COVID-19, of which 608 deaths with 401 new cases in the late 24 hours; in Galati city, are confirmed 354 case and 8 deaths of COVID-191.

Role of radiotherapy in multimodal treatment of neoplasic disease is well established, with important benefits in local control achievement, decreasing of local relapse risk (adjuvant radiotherapy) and reducing the mortality.

Is important that in this period, adjuvant or neoadjuvant oncological treatments, must to be continued, function of clinical-biological status, performance status and personal opinion of patient.

Visits in hospital must be reduced at minimum, any time is possible, in this period; also, the patients must be aware, by discussions with physicians, of risks and benefits, so the decision can be taken knowingly so multidisciplinary team can decide the delay of radiotherapy in certain circumstances.

Regarding breast cancer, experts from UK, Italy, Denmark, Australia, France, Brazil, have recently published, recommendations for radiotherapy performing in breast cancer, in COVID-19 pandemic period ${ }^{2}$.

One option can be avoiding the radiotherapy performing in patients with age $>65$ years or younger, with multiple comorbidities, in cases with tumors $<3 \mathrm{~cm}$, negative margins, G1-2, negative HER2 neu, that are scheduled for adjuvant hormonal therapy.
Modified fractionated radiotherapy can be an option, in selected cases without axillary invasion and no necessity of boost; can be chosen one of the following schemas:

Total dose $(\mathrm{TD})=28 \mathrm{~Gy} / 5 \mathrm{fr}$., $/ 5$ weeks, $1 \mathrm{fr} /$ week, dose per fraction $(\mathrm{d} / \mathrm{fr})=5.6 \mathrm{~Gy} / \mathrm{fr}$. or

$\mathrm{TD}=30 \mathrm{~Gy}, / 5 \mathrm{fr}$., $/ 5$ weeks, $1 \mathrm{fr} /$ week, $\mathrm{d} / \mathrm{fr}=6 \mathrm{~Gy} / \mathrm{fr}$.

$\mathrm{TD}=26 \mathrm{~Gy} / 5$ daily fractions $/ 5$ days, $\mathrm{d} / \mathrm{fr}=5.2 \mathrm{~Gy}$, conform FAST trial ${ }^{3}$

Five years results of multicentric phase III trial IMPORT Low, show non-inferiority in local control and also, late effects of partial irradiation of breast gland, with $\mathrm{TD}=40 \mathrm{~Gy} / 15 \mathrm{fr}$., comparative with whole breast irradiation with $\mathrm{TD}=40 \mathrm{~Gy} / 15 \mathrm{fr}$. or whole breast reduced dose $\mathrm{TD}=36 \mathrm{~Gy} / 15 \mathrm{fr}^{4}$.

Was demonstrated that $\mathrm{TD}=26 \mathrm{~Gy} / 5 \mathrm{fr}$. is radiobiological equivalent with $\mathrm{TD}=40 \mathrm{~Gy} / 15 \mathrm{fr}$. with identical results in terms of late effects 3 . Results of trial FAST, regarding 5 years local control is not yet published.

Axillary lymph node radiotherapy can be omitted in post menopausal patients, which requires whole breast radiotherapy, after surgery as first therapeutic sequence, with sentinel lymph node biopsy, for tumors $<2 \mathrm{~cm}$ (T1), RE (+), HER 2 (-), G1-2, with 1-2 invaded lymph nodes with macro metastases.

Other recommendation is referring at breast cancer patients with indication of adjuvant chemotherapy on mammary gland/ thoracic wall and lymph node areas. Hypofractionation, TD $=40 \mathrm{~Gy} / 15 \mathrm{fr} / 3$ weeks can be used, as many countries already use as standard treatment.

Regarding cervix cancer, European Society for Medical Oncology (ESMO) guide-lines recommend: discussions in multidisciplinary committee of every case, appreciation of vulnerability conditions (age $>65$ years old, cardiac diseases in previous, respiratory diseases), medical and logistical available resources ${ }^{5}$.

As we mentioned before, cases must be discussed taking into considerations, risks and treatment's benefits, and are considered for consultations as major priorities, cases with persistent symptomatology, vaginal bleeding patients potential unstable with complications after surgery or side effects during / after radiotherapy, or renal obstructions, anuria, at confirmed cervical cancer patient; also, major priority have new diagnosed patients, without priority of surgery intervention, with staging indication.

Medium prioritiy for medical consultation have patients with favorable status after hysterectomy, without complications, post-therapeutically and clinical 
Radiotherapy Delivering in COVID-19 Pandemic Context

visits, pelvic examinations, after palliative treatment for advanced disease or relapsed, which can be postpone until 2 months. Low priority have cases in follow-up after radical treatment for localized disease / early stage disease, which can be postpone until 6 months.

Regarding radiotherapy performing, major priority have cervix cancer cases in IB3, IIA, IIB, stage, with concurrent radio-chemotherapy indications. Other major indications are spinal cord compression syndrome, brain metastases (M1BRA), or other critical metastatic lesions ${ }^{5}$. Medium priorities represent salvage radiotherapy for central localized relapsed disease or retroperitoneal adenopathies. Low priority represents palliative radiotherapy for relapsing, asymptomatic with no surgery indication cervix cancer.

For colorectal cancers radiotherapy is recommended with high priority in cases with severe complications due to the disease evolution, bleeding, fractures, M1BRA, superior cava vein compression syndrome; medium priority represents: adjuvant radiotherapy, neoadjuvant radiotherapy in IInd, IIIrd stage rectal cancer, internal radiotherapy (Selective internal radiation therapy, SIRT, technique) for oligo-metastatic disease, in which, chemotherapy has no indications ${ }^{6}$; low priority have treatments for low evolution tumors in which an modest benefit is expected.

For low stage rectal cancer, hypofractionated radiotherapy is recommended, $\mathrm{TD}=25 \mathrm{~Gy} / 5 \mathrm{fr}$., $\mathrm{d} / \mathrm{fr}$. $=5 \mathrm{~Gy}$, +/- chemotherapy with capecitabine, instead of conventional fractionation. There are studies which show non-inferiority of short-course vs. long course fractionation schemas ${ }^{7}$.

In case of lung cancer, radiotherapy plays a crucial role. Lung cancer has a poor prognosis, has a rapid evolution, making radiotherapy postponing unacceptable solution ${ }^{8}$.

Under pandemic circumstances, the international guidelines and considerations mentioned, in early-stage non small cell lung cancer (NSCLC), stereotactic body radiation therapy (SBRT) a therapeutic option. For locally advanced NSCLC (unresectable stage III NSCLC), concurrent chemoradiation remains the elective option; the radiotherapy fractionation schema $\mathrm{TD}=55 \mathrm{~Gy} / 20 \mathrm{fr}$., $\mathrm{d} / \mathrm{fr} .=2.75 \mathrm{~Gy}$, is already used in some radiotherapy centers. Postoperative radiotherapy for NSCLC, for resected N2 disease, may be low priority than definitive radiotherapy ${ }^{8}$.

For small cells lung cancers (SCLC), consolidative radiotherapy can be delivered in $\mathrm{TD}=30 \mathrm{~Gy} / 10 \mathrm{fr}$., $\mathrm{d} /$ $\mathrm{fr}=3 \mathrm{~Gy}$. Thoracic irradiation after induction chemothe- rapy for advanced SCLC has been associated with increased survival, but the magnitude of this benefit is still debated ${ }^{8}$.

Palliative lung radiotherapy should be delayed when is possible or reserved for patients with life-threatening complications (superior vena cava syndrome or high volume hemoptysis). Fractionation schema can be: $\mathrm{TD}=20 \mathrm{~Gy} / 5 \mathrm{fr}, \mathrm{TD}=17 \mathrm{~Gy} / 2 \mathrm{fr}$. or $10 \mathrm{~Gy}$ in a single fraction $^{8,9}$.

In cases of head and neck squamous cell carcinoma (HNSCC), international guidelines recommend, in strong agreement and in high priority, not to postpone the initiation of radiotherapy, also in radical and in postoperative approach. HNSCC post-operative radiotherapy for minor risk factors represents lower priority ${ }^{10}$. For concomitant chemotherapy with conventional or mildly hypofractionated schedule of $\mathrm{d} / \mathrm{fr}$. $\leq 2.4 \mathrm{~Gy} /$ fraction was agreed. In selected cases, of early larynx cancer (T1N0), hypofractionated radiotherapy with $\mathrm{TD}=50 \mathrm{~Gy} / 16 \mathrm{fr}$., $\mathrm{d} /$ fr. $=3.125 \mathrm{~Gy}$ was recommended; for T2N0 disease, $\mathrm{TD}=55 \mathrm{~Gy} / 20 \mathrm{fr}$., $\mathrm{d} / \mathrm{fr}$. $=2.75 \mathrm{~Gy}$ was suggested; even if, there is limited evidence to support the use of hypofractionated radical radiotherapy over 4-5 weeks for locoregional advanced disease, authors recommended schedules including: $\mathrm{TD}=55 \mathrm{~Gy} / 20 \mathrm{fr}$., $\mathrm{d} /$ fr. $=2.75 \mathrm{~Gy}, \mathrm{TD}=62.5-64 \mathrm{~Gy} / 25 \mathrm{fr}$., $\mathrm{d} /$ fr. $=2.5-$ $2.56 \mathrm{~Gy}$ and $\mathrm{TD}=54 \mathrm{~Gy} / 18 \mathrm{fr}$., $\mathrm{d} / \mathrm{fr}$. = 3Gy $\mathrm{G}^{11,12,13,14}$.

We must be aware that typical presentation of COVID-19 is nonspecific and we must take into considerations that radiotherapy side effects can mimicking COVID-19 symptoms. Early symptoms may include running nose, low grade fever, sore throat, and cough. Many cancer patients on chemotherapy have low grade fever. Many lung cancer patients may have respiratory symptoms of varying degrees and a sore throat may be due to mucositis from head and neck radiotherapy ${ }^{15}$.

At the same time, rethinking the radiotherapy fractionations by adopting hypofractionated schedules may represent, in selected cases, the essential way to decrease the access of cancer patients to the hospital and limit the potential diffusion of COVID-19 ${ }^{16}$.

In Radiotherapy Centre from "Sf. Ap. Andrei” Emergency Clinical Hospital, Galati, Romania, in this pandemic context, was taken some general protection measures and also, measures for preventing and limiting of contamination with COVID-19: increase the distance between persons, protection equipment wearing, minimal epidemiological selection at the entrance in center (taking the body temperature and filling a document - own responsibility declaration, regarding 
pulmonary symptomatology and contact with other potentially infected persons); the symptomatic patients (dyspnea, cough, fever) had been tested. From $23^{\text {rd }}$ of April 2020 the SARS-COV2, PCR method testing, for non-symptomatic patients, has been initiated.

The time spent with patient was minimized, adopting phone conversations, sending the medical documents trough electronic channels and telemedicine. We have tried to schedule the radiotherapy treatment such that to decrease the time spent by patients in our centre, conforming to a timetable well established; also, patient had been advised to travel from home to radiotherapy center with personal vehicle (when is possible), avoiding public transportation, wearing protection gloves and masks (single use) during spending time in radiotherapy center also during transportation.

After each patient, were increased disinfection measures for patient's table in treatment room, undressing, medical and consultation cabinets. We did not interrupt treatments and we did not succeeded to reduce the patient's number on treatment, due to the high addressability to our center, taking into consideration administrative - territorial position (is no other radiotherapy center around $200 \mathrm{~km}$ ); we have an average of 45 patients /day / radiotherapy equipment, in conditions in which we have recently passed from $2 \mathrm{D}$ to $3 \mathrm{D}$ conformal radiotherapy technique (3DCRT), at final of December 2019. All cases are discussed in Oncological Commission.

We have tried to prioritize patients with curative chemoradiotherapy indication, patient which were in treatment at the moment of emergency state beginning, patients with spinal cord compression, mediastinal compression and M1BRA. We have reduced the number of continuous hospitalization (conforming to Ministry of Health), with increasing of day hospitalization number. For patients who required continuous

\section{References}

1. http://www.cnscbt.ro/index.php/situatia-la-nivel-global-actualizata-zilnic

2. C. E. Coles, C. Aristei, J. Bliss, L.Boersma, A.M.Brunt, S. Chatterjee, G. Hanna, R. Jagsi, O. Kaidar Person, A. Kirby, I. Mjaaland, et al. International Guidelines on Radiation Therapy for Breast Cancer During the COVID-19 Pandemic. https://www.esmo. org/guidelines/cancer-patient-management-during-the-covid-19-pandemic/breast-cancer-in-the-covid-19-era

3. 2018 ASTRO: FAST Trial Finds Long-Term Side Effects Similar for Once-Weekly and Conventional Breast Radiation Therapies. https://www.ascopost.com/News/59403

4. A.M. Kirby, I.S. Bhattacharya, M. Wilcox, J.S. Haviland. The IMPORT LOW Trial: Collaborative Research Accelerates Practice hospitalization, SARS-COV2 testing has been performed, before hospitalization.

On the other hand we have applied hypofractionation schemas, for selected patients, new in treatment, according to their option, conforming ESMO and $E u$ ropean Society for Radiotherapy and Oncology (ESTRO) recommendations.

Also, medical personnel have been self-monitorized measuring the body temperature (2 times in 24 hours) and monitoring respiratory symptoms.

Until the moment of this article writhing, we haven't recorded any suspect or confirmed COVID-19 infection amongst medical personnel, either oncological patient infected with COVID-19.

\section{CONCLUSIONS}

COVID-19 pandemic affected our life style, daily routine, but we didn't treat with less importance neoplasic patients. We have tried to balance treatments with patient's and medical personnel protection, and that was the main our concern.

When we adapted radiotherapy fractionation schemas, we took into consideration the recommendations of expert's panel from international societies such as), ESMO, ESTRO, American Society for Radiotherapy and Oncology (ASTRO), World Health Organization (WHO), following the institutional rules, without compromising the quality of medical act.

Compliance with ethics requirements: The authors declare no conflict of interest regarding this article. The authors declare that all the procedures and experiments of this study respect the ethical standards in the Helsinki Declaration of 1975, as revised in 2008(5), as well as the national law. Informed consent was obtained from all the patients included in the study.

Change in Breast Radiotherapy. Clinical Oncology 31 (2019) 5-8

5. https://www.esmo.org/guidelines/cancer-patient-management-during-the-covid-19-pandemic/gynaecological-malignancies-cervical-cancer-in-the-covid-19-era

6. https://www.esmo.org/guidelines/cancer-patient-management-during-the-covid-19-pandemic/gastrointestinal-cancers-colorectal-cancer-crc-in-the-covid-19-era

7. Samuel Y. Ngan, Bryan Burmeister, Richard J. Fisher, Michael Solomon, David Goldstein et al. Randomized Trial of Short-Course Radiotherapy Versus Long-Course Chemoradiation Comparing Rates of Local Recurrence in Patients With T3 Rectal Cancer: Trans-Tasman Radiation Oncology Group Trial 01.04. J Clin Oncol. 201230:3827-3833. 
8. Wu AJ, Rimner A, Shepherd AF, Gelblum DY, Shaverdian N, Yorke E, Simone CB II, Gomez DR, Thoracic radiation therapy during COVID-19: provisional guidelines from a comprehensive cancer center within a pandemic epicenter, Advances in Radiation Oncology (2020), doi: https://doi.org/10.1016/j.adro.2020.04.008.

9. Rodrigues G, Videtic GM, Sur R, et al. Palliative thoracic radiotherapy in lung cancer: An american society for radiation oncology evidence-based clinical practice guideline. Pract Radiat Oncol 2011;1:60-71

10. David J. Thomson, FRCR, 1 David Palma, Matthias Guckenberger et al. Practice recommendations for risk-adapted head and neck cancer radiotherapy during the COVID-19 pandemic: an ASTRO-ESTRO consensus statement. https://www.astro.org/ ASTRO/media/ASTRO/Daily\%20Practice/PDFs/COVID-Thomson-et-al(ROB).pdf

11. Tobias J.S., Monson K., Gupta N. et al. Chemoradiotherapy for Locally Advanced Head and Neck Cancer: 10-year Follow-Up of the UK Head and Neck (UKHAN1) Trial Lancet Oncol 2010; 11: 66-74.

12. Jacinto A.A., Filho E.S.B, de Souza Viana L. et al. Feasibility of concomitant cisplatin with hypofractionated radiotherapy for locally advanced head and neck squamous cell carcinoma BMC Cancer 2018; 18: 1026

13. Meade S., Gaunt P., Hartley A. et al Feasibility of Dose-escalated Hypofractionated Chemoradiation in Human Papilloma Virusnegative or Smoking-associated Oropharyngeal Cancer Clin Oncol (R Coll Radiol) 2017; 30: 366-374

14. Thomson D.J., Ho K.F., Ashcroft L. et al. Dose intensified hypofractionated intensity modulated radiotherapy with synchronous cetuximab for intermediate stage head and neck squamous cell carcinoma Acta Oncol 2015; 54: 88-98

15. Tey, J., Ho, S., Choo, B.A., Ho, F., Yap, S.P., Tuan, J.K.L., Leong C.N., Cheo, T., Sommat, K., Wang, M.L.C., Navigating the challenges of the COVID-19 outbreak: perspectives from the radiation oncology service in Singapore, Radiotherapy and Oncology (2020), doi: https://doi.org/10.1016/ j.radonc.2020.03.030.

16. Achard V, Tsoutsou P, Zilli T, Radiotherapy in the time of the Coronavirus pandemic: when less is better, International Journal of Radiation Oncology, Biology, Physics (2020), doi: https://doi org/10.1016/j.jijrobp.2020.03.008. 
